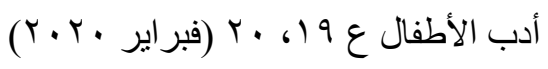

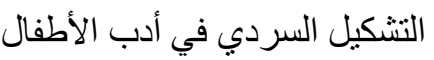

\title{
التثكيل السردي في أدب الأطفال وأبعاده الثقافية
}

أ. كمال اللهيب

باحث في أدب الأطفال

يُعد الأدب من أصدق أدوات التعبير عن الهوية وعن رؤية الإنسان لواقعه المحيط

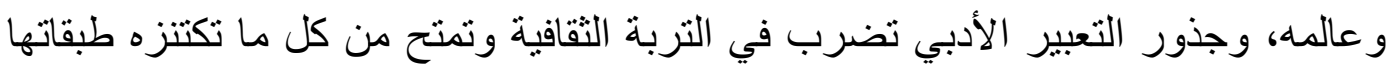
المعرفية والتاريخية والسياسية والدينية... إلخ. فالتعبير الأدبي بالأخير يكون محصلة تفاعل الوجدان و الفكر مع عناصر تللك الطبقات.

ويمكن تصور العلامة السردية كعملة ذات وجهين، على وجهها الأول يوجد الدوال/ التثكيلات السردية، وينهض ذلك المستوى بالثكل الجمالي للعمل وتتجسد فيه القيم الجمالية المهيمنة لاى الجماعة الثقافية، والتي يسعى العمل إلى مو افقتها أو الإضافة إليها أو خرقها،

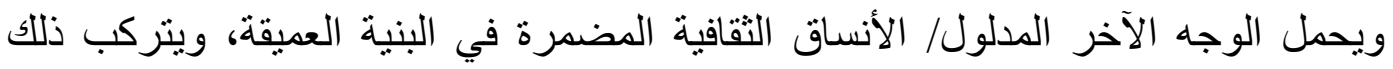

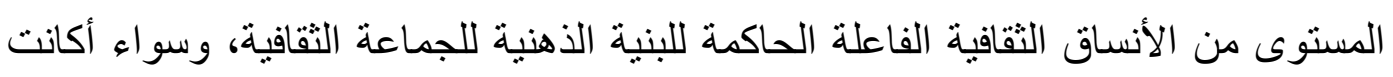
الأنساق واعية أم لا واعية فإنها تحكم وتنظم رؤية الجماعة وتصور اتها عن نفسها وعن العالم، وينعكس تمثيل نلك الأنساق على آليات التشكيل السردي، عبر عمليات تحويلية يمر

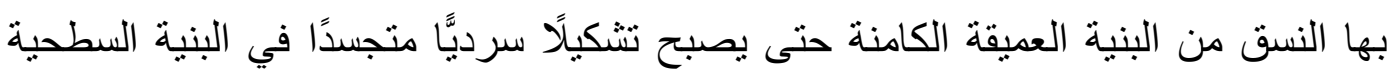
للعمل. و انطلاقًا من هذا التصور يسعى البحث إلى مقاربة ملامح التشكيل السردي في أدب

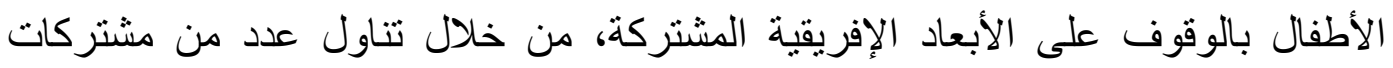
مقو لات التثكيل السردي: الثخصية والحدث و الزمكانية، باعتبار ها تمثيلات جمالية لأنساق

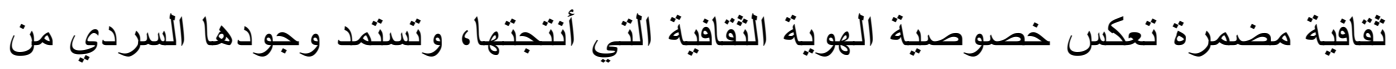

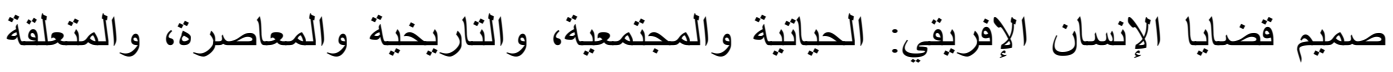

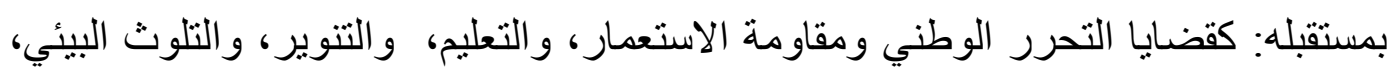
و العنف، واستخدام الدين ذريعة لتبرير العنف ضد الآخر. وسوف يتناول البحث عددًا من تشكيلات السرد وتقنياته في أدب الأطفال من خلال مبحثين رئيسين: مبحث الثخصية و الحدث، و وبحث الزمكانية. 


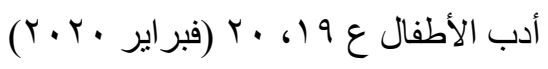

التشكيل السردي في أدب الأطفال

\section{أولاً - الشخصية والحدث:}

اتخذ علم السرد Narratology من التوازي بين الجملة الفعلية والقصة مرتكزًا

نظريًا في الممارسة التحليلية للنصوص، ويمتد هذا التوازي ما بين ركني الإسناد في الجملة: الفعل/المسند، و الفاعل/المسند إليه، والشخصية و الحدث، فترتبط الثخصية السردية بما يسند إليها من صفاتٍ و أحداث ووقائع داخل الإطار السردي.

و عندما يقوم كاتب الأطفال ببناء شخصياته الفنية فإن تشكيلها لا يأتي اعتباطيًا من فر اغ؛ بل ينبع من صميم الرؤية الشعورية أو اللاشعورية المترسخة داخله، و الوثيقة الصلة بهوية الذات الثقافية التي يحمل مهمة تقديم رؤيتها للعالم من خلال عمله. و الهوية الثقافية عندما تتخذ بُعدًا جمعيَّا تصبح كلً مركبًا من جميع ما مرت به ربه الجماعة الثقافية من خبراتٍ وتر اكماتٍ اجتماعية ودينية وسياسية ونضالية... إلخ، وما تمر به في ظرفها التاريخي الراهن، إضافة إلى ما تتطلع إليه في مستقبلها، وتتعكس تلك المكونات الجوهرية المنظمة لذهنية الجماعة في عالم الو اقع على تشكيل الذوات التخييلية في العالم السردي.

وتزتبط مصر بقارتها الإفريقية "الجوهرة السمراء" ارتباط الجغر افيا والتاريخ؛

فنهر النيل قاسمٌ مشتركُّ بين دول حوض النيل، ومرت مصر في تاريخها المعاصر بخبراتٍ مشتركة ومشابهة لما مرَّ به الأشقاء الأفارقة من التعرّض للاستعمار، و النضال من أجل التحرير، و الثورة ضد الظلم، وما إن نالت مصر حريتها حتى شر عت في مساعدة أثقائها في إفريقيا لنيّل حريتهم من الجزائر إلى الكونغو، ثم جاءت مرحلة ما بعد الاستعمار، والتي فرضت قضايا مصيرية، منل: التنوير والتعليم والديموقر اطية والكفاح ضد العنصرية، و أصبح الرهان في الوقت الراهن على قضايا تتعلق بمستقبل القارة، أهمها: التعصب الديني و اتخاذ الدين ذريعة لتبرير العنف ضد الآخر.

\section{أنساق الثخصية:}

تلك الخبرات التاريخية المشتركة التي انصهرت في بوتقة الجسد الإفريقي بمكن استجلاؤ ها بالوقوف على بعض خلاياه، لاستكناه الجينات التي يحملها الكيان في مجمله. فهي تتعكس على أنماط الشخصية السردية في أدب الأطفال، ويمكن استجلاء ثلاثة أنساق رئيسة في إطار الارتباط بالبعد الإفريقي. 


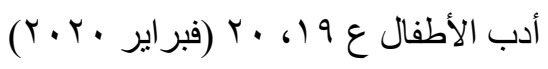

التشكيل السردي في أدب الأطفال

\section{نسق البطولة الوطنية والنضال:}

رزحت القارة الإفريقية رَدحًا من الزمن تحت وطأة الاستعمار الذي استهدف سَلْب

خير ات شعوبها ومواردها الطبيعية وجعلها سوقًا لمنتجاته، وعَامَلَ أهلها معاملة عنصرية ميز فيها الأقليات الأجنبية عن السكان الوطنيين، في تللك الأجواء من الإحساس بالظلل و الاستغلال والتمييز العنصري الذي فرضه الاستعمار تجلى داخل الثخصية الإفريقية نسق التضحية والفداء والمقاومة والبطولة، فظهر الزعماء والأبطال الوطنيون والثوار: عمر المختار في ليبيا ضد الاستعمار الإيطالي، نيلسون مانديلا في جنوب إفريقيا، وباتريس لومومبا في الكونغو ضد الاستعمار البلجيكي، وكوامي نكروما في غانا ضد الاستعمار الإنجليزي، وتوماس سنكارا في بوركينا فاسو، وشاركت المرأة الإفريقية في تحرير أوطانهن فظهرت نجمات لامعة في سماء النضال الإفريقي، مثل: تيتو بتول التي ساهمت في تحرير إثثيوبيا من الاستعمار الإيطالي، وإلياء اسنتيوا في غانا التي قادت جيشًا ضد الاستعمار الإنجليزي، وجميلة بوحريد في الجزائر ضد الاستعمار الفرنسي، وهذه النماذج التاريخية الواقعية المثرقة وغيرها الكثير قد أعطت السند المرجعي لظهور نسق البطولة الوطنية و النضال في الأدب.

وقد تعرضت مصر للاحتلال الإنجليزي، ويصف عبد التواب يوسف أجواء تلك الفترة التي رزحت على مصر في مقدمة رواية "أم حنان":

في سابق العصر و الزمان، كان هذا المكان، قبل حفر القنال، بحرًا من الرمال.. وفجأة نبتت فوقه ـ على ضفة القناة- ومن حول بحيرة التمساح، مدينة الإسماعيلية.. وقد عسكر فيها الإنجليز منذ احتلوا مصر عام 111 ا. وناضلت مصر ضدهم، وهبت عليهم في ثورة 91919 و أخمدوها، و عقب الحرب العالمية الثانية تم جلاؤهم عن القاهرة تحت ضغط الثعب، وتمركزوا غرب القناة.. ومع النصف الثاني من القرن العثرين ــ 1901 ـ هبت مصر في ثورة ضدهم، تقاتلهم داخل معسكر اتهم وفي مدن القناة، وأصبح النداء على كل

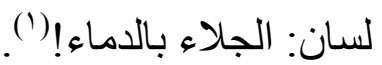
تمنلت شخصية المناضل الثائر على الاستعمار في أدب الأطفال ولم تقصر على

الذكور ، و إنما عكست صفحات الأدب بطولة المر أة وتضحيتها من أجل وطنها. في رواية "أم حنان" تطالعنا شخصية "أم حسن" التي تلقى ابنها "هذا البطل ابن السنوات العشر، رصاصة في صدره، وسقط شهيدًا"(؟)، فإذا بها تنتفض ثأرًا لابنها ولوطنها 


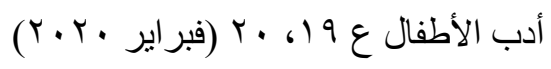

التشكيل السردي في أدب الأطفال

من القتلة و "تحمل الموقِد مشتعلًا في يدها قرب صدرها، وتحمل على وجهها أمار ات عزمٍٍ

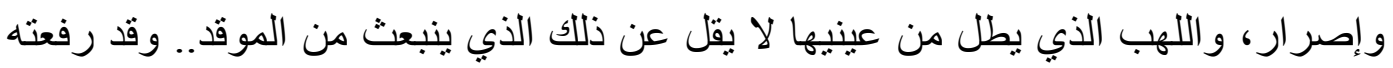

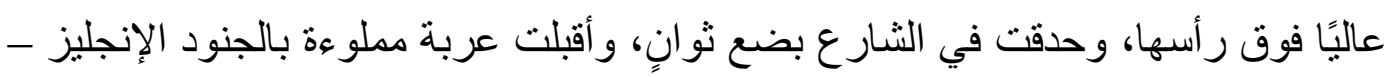
قتلة ابنها- وفي لمح البصر، قذفت بالموقد في قلب السيارة المسرعة، و وإذا بها شعلة نارٍ

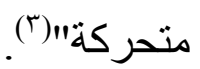

وكأن هذه المر أة التي أنهت حياتها في المقاومة و الثأر من المستعمر قد أورثت ابنتها

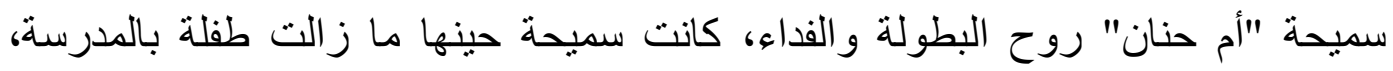
و عندما كبرت كانت حرب أكتوبر الدجيدة في أوارها، فترسبت في ذهنها ولها جميع الخبرات الوطنية التي مرت بها مصر في تللك الفترة الحاسمة من تاريخها. ويكثف ما يُسند إلي شخصية سميحة من سماتٍ بنائية عن تر اكم مقومات اجتماعية وسياسية مستمدة من الواقع الوطني المصري الذي يعكس حال الواقع الإفريقي، وهذه منه

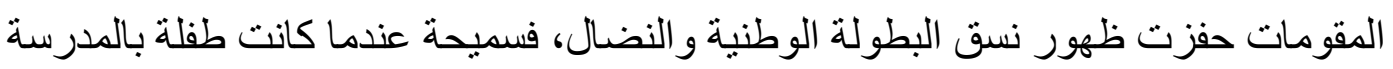

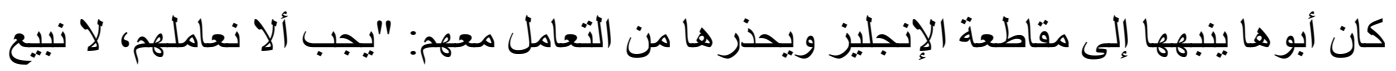

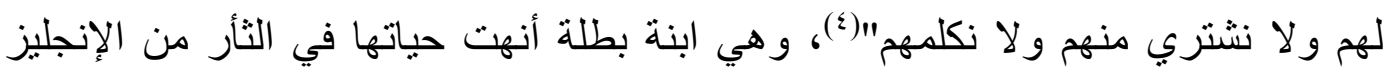

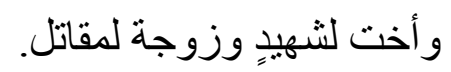

تلك المقومات على مستوى بناء الثخصية هيّاتث لتمثيل نسق البطولة و التضحية على مستوى الحدث السردي، فتقبل سميحة الذهاب في مهمة خطيرة وسط معسكرات

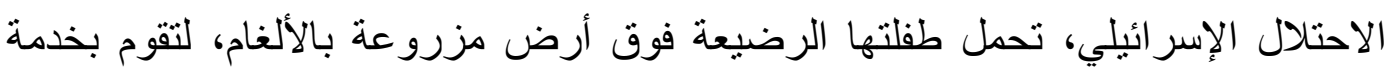

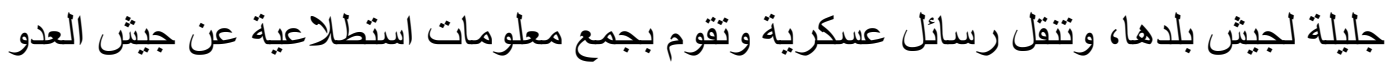

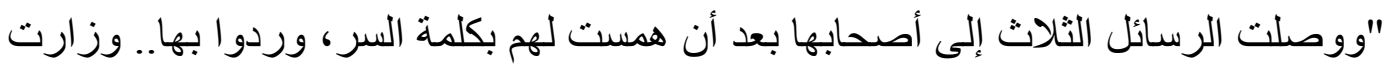

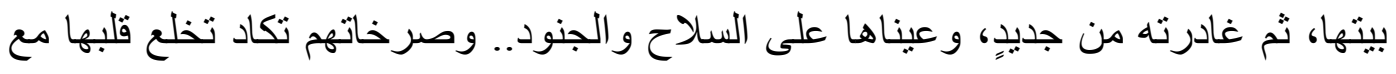

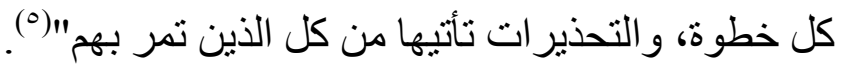
في المحن التي يمر بها الوطن يتجلى الجوهر الحقيقي للشخصية الوطنية، وفي

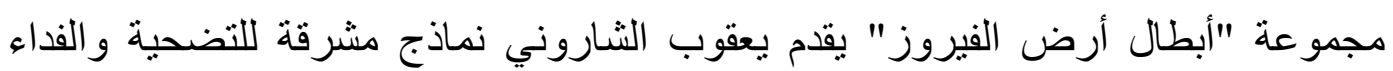
تستمد وجودها السردي من نسق البطولة والنضال الفاعل في البنية العميقة للشخصية

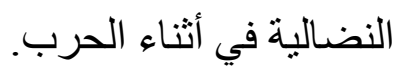




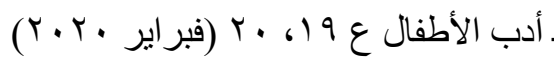
النشكيل السردي في أدب الأطفال

تأخذ تلك البطولات خطَّا تطوريَّا يبدأ من التجهيز لحرب أكتوبر المجيدة ثم في أثناء الحرب، وحتى الانتصار والسيطرة على خط بارليف، ليكثف ذلك التتابع الزمني على تأصُّل البطولة في الروح الوطنية واستمر اريتها على مدار الزمن، و أنها ليست قاصرة على لحظة زمنية و احدة.

والإنسان الإفريقي عامة، والمصري الذي هو جزء لا يتجزأ منه، يؤمن بالقدرة

الإلهية و عدالتها ومساندتها له في قضاياه العادلة، وتكثف قصة "إرادة الله" عن ذلك النسق الديني الفاعل، فقبل الحرب بثلاثة أيام وفي أثناء نقل المعدات تمهيدًا للعبور العظيم، "كان الظلام حالكًا فاضطرت السيار ات إلى إضاءة أنوار ها، وكان من الممكن أن يكتشفها العدو، خاصة، وأن الطابور المتحرك بضم أكثر من مائتي سيارة، لكن فجأة، انتشر ضبابٌ كثيف غطّى المنطقة بأكملها وتعذرت الرؤية، وبذلك وصلت السيارات إلى المناطق المحددة لها"(ا). في غياب عن أعين العدو، وكان من الممكن أن تكتشف دوريات استطلاع العدو وصول تللك المعدات، ولكن قبل ظهور أول ضوء من تلك الليلة "هبت عاصفة رملية غطت المنطقة كلها، وجعلت الرؤية متعذرة، ولم تتوقف تلك العاصفة إلا بعد وصول شباك التمويه

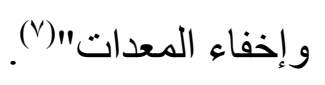

في قصة "بطولة شهيد" تحُول مدافع العدو دون تقدم مجموعة المشاة نحو اقتحام خط بارليف، وفي غمرة الموقف العصيب وتحت إطلاق النيران الكثيفة، "فجأة شاهدت إحدى المجموعات أحد أفرادها ينظر إلى الأمام، ثم إلى أفراد المجموعة، ويقول لهم: انتظروا، واستعدوا و تقدموا من بعدي، و اندفع كالصاروخ يجري في اتجاه فتحة أحد المدافع في الموقع المُعادي، ثم ألقى بجسمه فوق الفتحة، وقبل أن يلفظ أنفاسة الأخيرة، كان قد دفع بيده قنبلة يدوية داخل الموقع.. ودوى انفجار هائل"(^).

\section{الثخصيات الضد للبطولة والنضال:}

أدب الأطفال لا يقدِّم صورة ملائكية عن العالم، لا يلبث الطفل أن يكتشف عدم

صحتها عندما ينضج و عيه وتتفتح مداركه، بل يقدِّم صورة منوازنة عن العالم، فإلى جوار نموذج الخير هنالك نموذج الثر الذي يتم تقديمه بهدف تبصرة الطفل بمواطن الخطأو الزلل، و على أن يكون الانتصار لقيم الخير والحق والجمال، وفي حدود قدرة الطفل على تلقي النماذج غير الخيرة. 


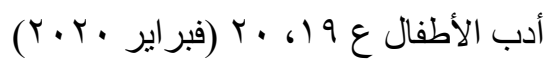

التشكيل السردي في أدب الأطفال

وقد كان وجود الاستعمار سببًا في تجلي نماذج البطولة والفداء والمقاومة، وأيضًا

في ظهور النموذج الضد، نموذج العميل (الجاسوس) الذي يعمل لحساب العدو.

تقدِّم رواية "عميل في المصبدة" نموذج العميل من خلال شخصية "رشدي

فرحات"، وتتتبع حياته إلى أن يتم القبض عليه ومحاكمته بتهمة الخيانة العظمى.

ولِدا رشدي عام r و 9 أثناء الاحتلال البريطاني، وشبَّ وسط حالة الحِر الك الثوري

و المطالبة بالاستقلال، لكن شيئًا من ذلك الحِراتك لم يمس وجدانه، فذاته هي محور حياته ولم

يكن يأبه بشيءٍ غير نفسه.

وتتبع ملامح بناء الثخصية السردية للعميل يكثف عن تر اكم مقومات عدم الانتماء

التي أوصلته إلى حدث الخيانة العظمى، فعندما طلب مدرس اللغة العربية من تلامبذ الفصل كتابة موضوع عن "ما الذي تريده لمستقبلك؟"، كانت إجابته هي "المال و الترحال وخلو البال"، ويكثف له زميله خطأه قائلاً:

هل من الممكن أن يعيش إنسان في بلد محتل، وهو خالي البال؟!.. وطننا يا رشدي

همّه ثقيل، ويجب أن يشغل بالنا ليل نهار.. أرجوك أن تعيد النظر في آر ائك هذه(9).

وفي شبابه اتجه للعمل مع القوات البريطانية في منطقة القناة؛ "لأنهم يدفعون أجورًا

أكبر، وكلما عاتبه أحدهم أو توجه إلبه باللوم، ردَّد عبارة سخيفة يطلق من بعدها ضحكة هستيرية رخيصة.. كان يقول: اللي يتجوز أمي أقول له يا عمي"(·(')

والأنانية وعدم الانتماء أوصلته إلى التهرب من أداء الواجب الوطني، فعندما

"استُدعي للتجنيد فرض على أهله أن يبيعوا قطعة أرضٍ صغيرة، كانت هي البقية الباقية من أملاك الأسرة؛ ليدفعو اله ما كان يُسمى يومئذٍ البدلية"(1').

ويستمر بناء شخصية "رشدي" على طول مسار السرد كاثفًا عن نقيصة تلو

أخرى، وتكون المحصلة النهائية سقوطه في بئر العمالة للعدو الإسرائيلي، والذي تسعى الرواية من خلال عرضها لهذا النموذج السلبي إلى و التوعية و التحذير من مغبته.

\section{النسق التثويري:}

المطالبة بالحقوق تأتي بعد معرفتها، والمعرفة طريقها العلم والتعلم، وقد استندت .

حركة النضال الوطني إلى شخصياتٍ تنويرية، تعلمت ووعت حقوقها وحقوق شعوبها، وحملت مشاعل العلم من منابعه إلى أوطانها لتنير جنباته، وقد تمثلت في أدب الأطفال نماذج الثخصيات التنويرية التي توظف العلم في الكفاح ضد الظلم، ففي سلسلة "مغامرات أرنباد" 


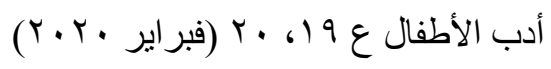

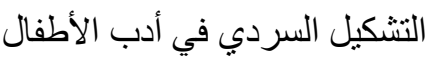

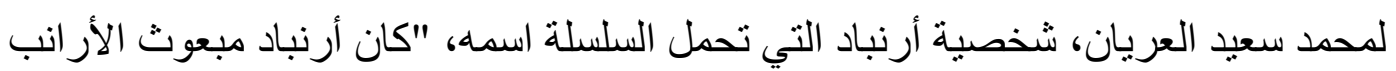

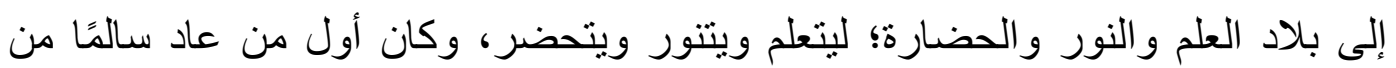

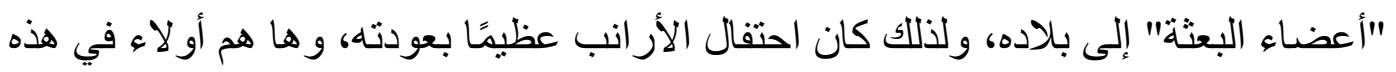

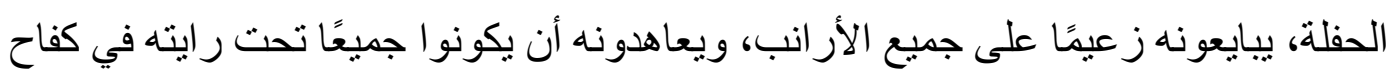

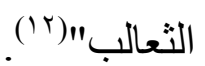

\section{الثخصيات الضد للتنوير:}

المعرفة مصباح التتوير، وكل ما يحول دونها أو يعمل على إطفاء نورها يعرقل الوصول إلى الغاية النهائية، ومن النماذج الضد للتنوير، شخصية ملك الظلام المقنَّع في

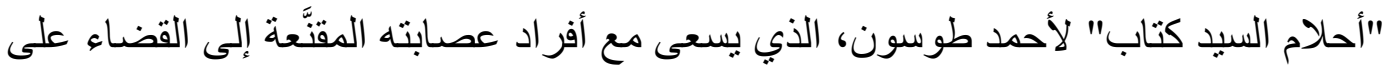
المعرفة عن طريق الحصول على جميع الكتب للتخلص منها، ويرتبط الوصف المسند

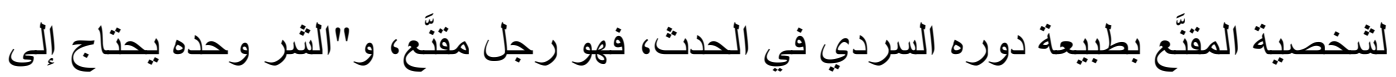
قناع ليتخفي وراءه!"("')، ومع الوصف يشترك الحوار في كثف أبعاد شخصيته و غاية

$$
\text { برنامجه السردي عندما يتحدث مع السمسار: }
$$

"اذهب أنت وسأنتظرك هنا. و لا تنس كتابًا واحدًا، فأنا أريدها كلها، لا أريد أن يبقى

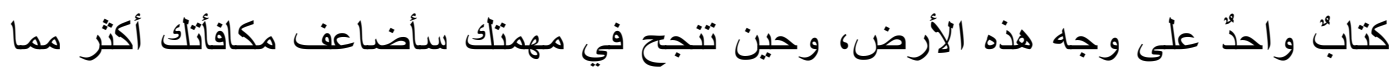

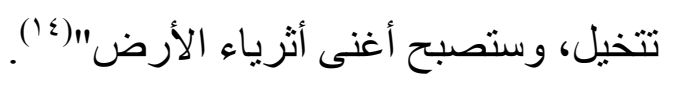

وينتهي مخطط عصابة المقنَّعين الأربعة بالفشل ويتم القبض عليهم، ولكن الثر لا لاهي

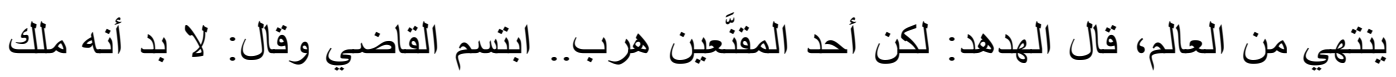

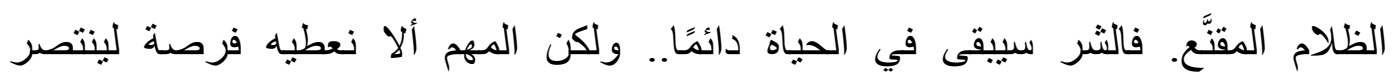
علينا"(10)

فأدب الأطفال كما أثشرنا لا يُقِّمّ للطفل رؤية ملائكية عن العالم؛ فالخير موجود و الثر موجود، و المعيار فيما يُقََّّ للطفل أن يكون الانتصار لقيم الخير و الحق و الجمال.

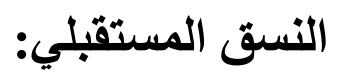

من حق الثعوب الإفريقية أن تطمح إلى مستقبلٍ أفضل، وتحقيق الحلم يتطلب

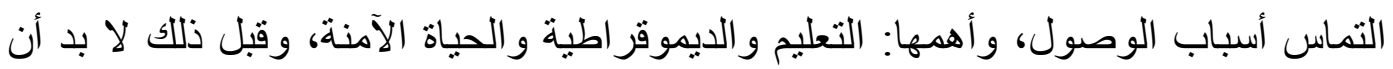

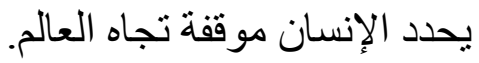




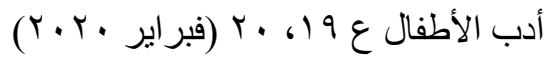
النشكيل السردي في أدب الأطفال

أخذ التعليم ينتشر تدريجيَّا في شعوب إفريقيا في مرحلة ما بعد الاستعمار؛ لأن

الثعوب المحررة أدركت أنه وسيلتها للمستقبل وللتمسك بهويتها التي عمل الاستعمار على محوها، فسعت بعض البلدان إلى استعادة لغتها القومية بعد أن فرض عليها الاستعمار لغته، و ازدادت المؤسسات التعليمية، وكان لمصر دور ها التاريخي في هذا السياق مع أثقائها عبر مؤسساتها التعليمية والأزهر الثريف في إرسال البعثات التعليمية والمعلمين و استقبال الوفود من طلاب العلم.

وقد أقرت الاتفافية الدولية لحقوق الطفل عام 919 احق الطفل في التعليم في المادة

(Y^)، و التي تتص على أن: للطفل الحق في التعليم، ومن واجب الدولة أن تضمن أن يكون التعليم الابتدائي مجانيَّا و إلز اميَّا، وأن تشجع على توفير مختلف أشكال التعليم الثانوي و إتاحته لكل طفلٍ، وأن يكون التعليم الأعلى متاحًا للجميع على أساس الكفاءة، ويكون الانضباط المدرسي متفقًا مع حقوق الطفل وكر امته، وتشارك الدولة في التعاون الدولي لتنفيذ هذا الحق. ولكن قد يحول دون تعليم بعض الأسر لأبنائها بعض الظروف الاقتصادية كضيق ذات اليد، أو الجغر افية كالعيش في الأماكن النائية عن مؤسسات التعليم، أو ثقافية اجتماعية كغياب الوعي في بعض البيئات بتعليم البنات، و اعتباره لا طائل منه. أكد أدب الأطفال ضرورة التعليم باعتباره حقًّا، وتمثلت نماذج سردية تؤكد ضرورة التغلب على كل المعوقات التي تحول دونه وخاصة تعليم البنات. و تقدِّم قصة "زينة تصعد القمر" لفاطمة المعدول نموذجًا للبنت التي تكافح ضد كل الصعاب التي تقف أمام حقها في التعليم، من خلال شخصية "زينة عبد الله، بنت في الخامسة عشر من عمرها، تعيش في قرية صغيرة من قرى صعيد مصر" (7'1)، و هي تساعد أمها و إخوتها في المنزل و أبيها في الحقل، و عندما تأوي إلى حجرتها في الليل يعاودها حُلمها في "مدرسة جميلة تذهب إليها كل يوم و تتعلم فيها الحروف.. و الكلمات.. و الأرقام.. وتقر أ كتبًا وقصصًا وحكايات"(V')، ولكنها تعلم أن حُلمها مستحيل لأنها "أصبحت كبيرة ولن تقبلها أية مدرسة"(^^)، ولكن يشاء القدر أن يمنحها فرصة لتحقيق حُلمها عن طريق "مدرسة الفصل الواحد، وهي مدرسة لا تتقيد بسن معينة، وتذهب إليها الفتيات اللائي حُرِمن من التعليم في طفولتهن"(19)، ويلوح لها الحُلم لكن الطريق تعترضه العقبات الاجتماعية والجغر افية؛ "فالمدرسة ليست في قريتها بل في القرية المجاورة التي تبعد حو الي عشرين كيلو مترًا عن قريتها"(·r)، وأخوها الصغير علي يضحك على فكرتها: 


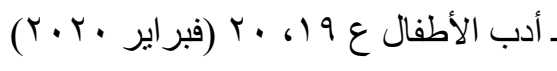

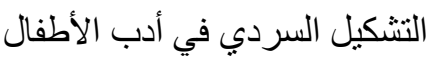

ـهل ستذهبين إلى المدرسة مثلنا وترتدين "مريلة" وتحملين "شنطة" وكتبًا

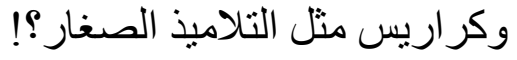

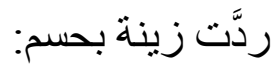

- سأرتدي جلبابًا نظيفًا.. وسأحمل "شنطة" فيها كتبّ وكر اريس.. فهذا ليس عيبًا،

$$
\begin{aligned}
& \text { بل هو شرف يجب أن أفخر به"('ا") } \\
& \text { وجَدّتها تتعجب قائلة: }
\end{aligned}
$$

- ولكن يا ابنتي هل ينفع التعليم في الكبر؟؟ إننا نعرف أن التعليم في الصغر كالنقش في الحجر و التعليم في الكبر لا فائدة منه ولا منفعة.

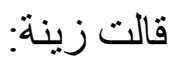

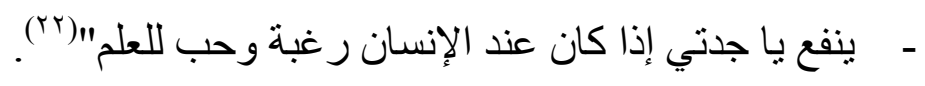

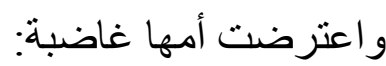

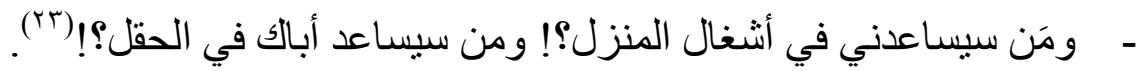
وأمام إصرار زينة على تحقيق حُلمها والتغلب على العقبات التي تعترضها، ووصولها في نهاية السرد إلى ذللك الحُلم، تصبح تمثيلاً سرديًّا لنسق الحق فئَ في التعليم من أجل

\section{الايموقر اطية:}

الديموقر اطية أحد أهم سبل الوصول الآمن إلى المستقبل المنشود، بكل ما تشتمله من قيم الحرية والعدالة والمساواة والتعددية وقبول الآخر، ومن تللك القيم تتبع الحقوق الثابتة للطفل التي نصت عليها الاتفاقية الدولية لحقوق الطفل، ومنها: عدم التمييز في المعاملة (مادة

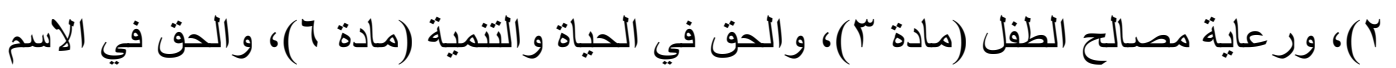

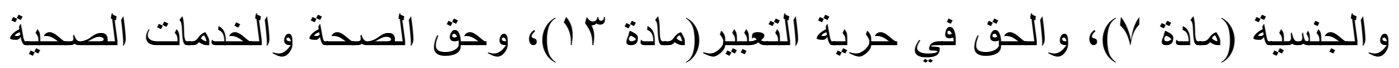

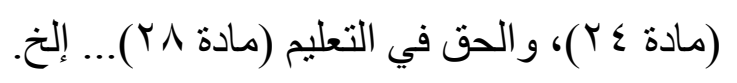

ترتكز الممارسة الديموقر اطية على تعدُّد الر أبي وتداوله و النزول على رأي الأغلبية،

ويُعد ذلك هو النسق الحاكم للممارسة الديموقر اطية بداية من الممارسات الاجتماعية للأفراد ووصولاً إلى الممارسات المؤسسية، في قصة "الثورى شورتك"، تتمثل تلك الممارسة

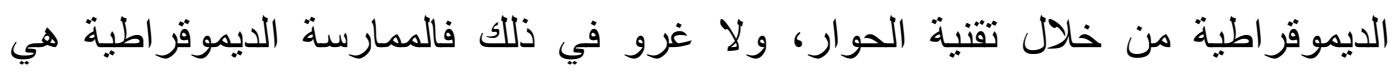
بالأساس ممارسة حوارية تتأسس على تعدُّد الأصوات. 


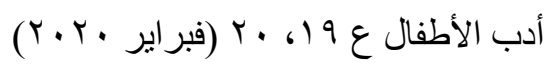
التشكيل السردي في أدب الأطفال يتداول أعضاء فرقة الناشط علي في اجتماعهم اقتراح كريم حول تغيير مكان

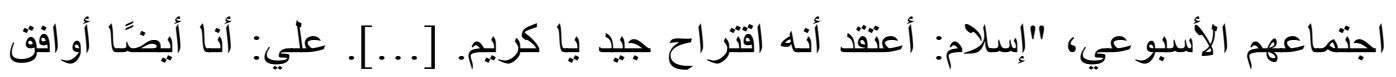

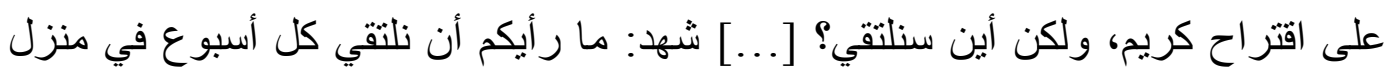

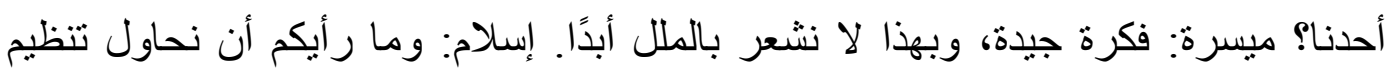
رحلة كل أسبوع إلى أحد الأماكن السياحية في مصر؛ لنستمتع بآثارنا ومعالمنا السياحية الجميلة، وفي الوقت نفسه نناقش الجديد من الحقوق و القوانين، ونتفق مع أسرنا أن يصحبونا

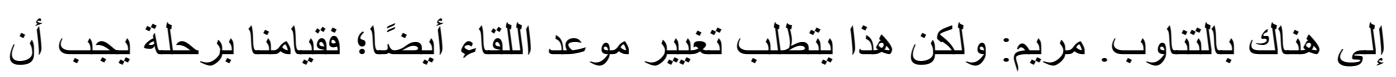

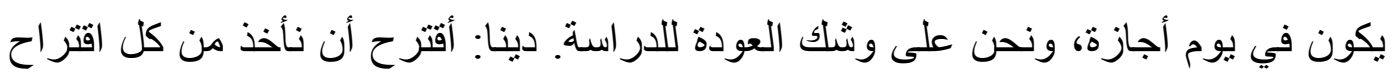

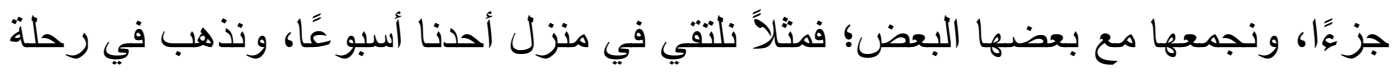
الأسبوع النالي، ثم نلتقي في النادي الأسبوع الذي يليه، وهكذا نكون استفدنا من كل فل

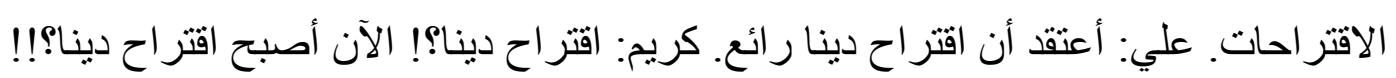
كل شيء أقترحه تتسبونه لآخرين غيري؟! علي: نحن نتشاور يا كريم، ولم أقصد أن أقلل من

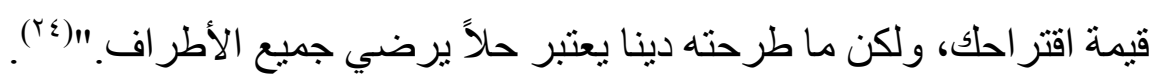

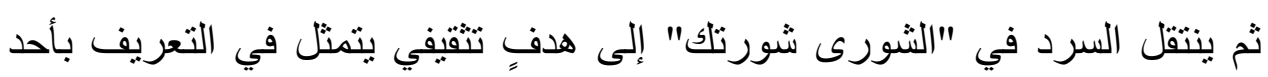

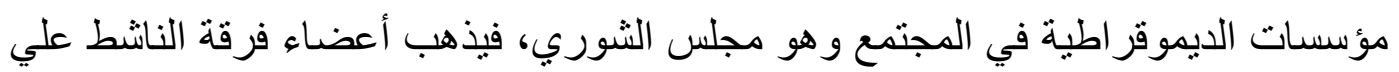
إلى منزل محب ويلتقون بخاله الذي يحدثهر عن دور مجلس الثنورى وتاريخه وتكوينها.

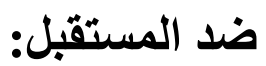

\section{اللامبالاة وعدم اتخاذ موقف في الحياة:}

الطريق نحو المستقبل مرهون بتحديد الإنسان لموقفه من حاضره، ولن يعرف الفرد

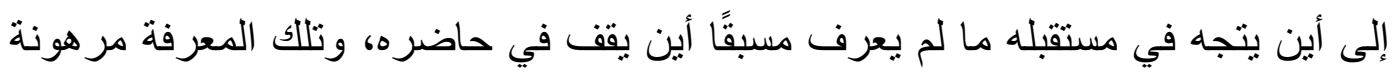

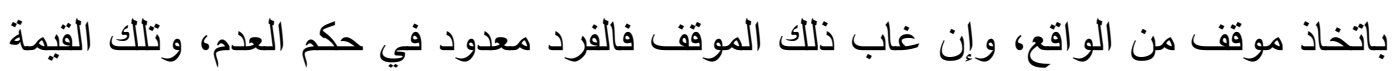

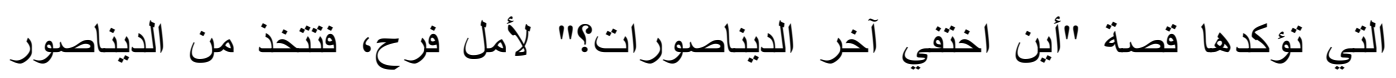

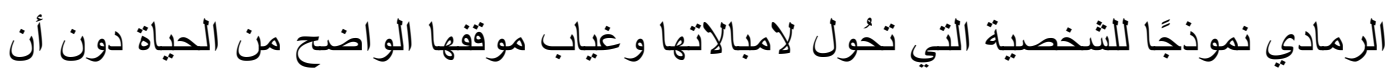

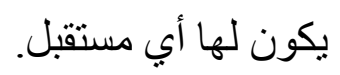

يتم توظيف الوصف الخارجي و الداخلي المسند إلى الثخصية/ الديناصور الرمادي

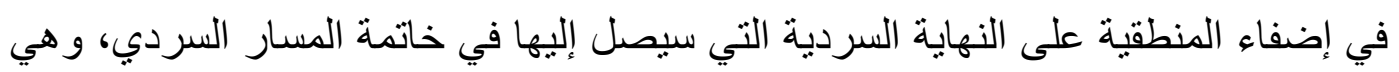

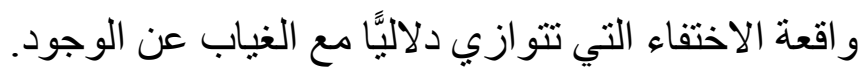




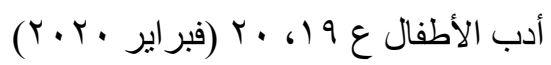
التشكيل السردي في أدب الأطفال عندما استيقظ الديناصور الرمادي ولم يجد أقر انه من الديناصورات "لم بشغل باله ويسأل أين ذهبو ا؛ لأنه لم يكن يشغل باله أصلاً بالسؤال عن أي شيء"(ro(، وكان يأكل أي شيءٍ، و "كان يشرب من الماء العذب أو من ماء البحر لا فرق، فهو لا يحب الماء العذب و لا يكره الماء المالح، كان يتحرك هنا و هنالك، ينام أسفل شجرة أو على سفح جبل، لا يهم. كان الديناصور الرمادي لا يحب و لا يكره، لا يفضل و لا يرفض. كان يعتقد أن كل شيءٍ في الدنيا رمادي؛ مزيج من الأبيض و الأسود معًا"(זr).

الديناصور الرمادي عندما "تعب من المسير و غلبه النوم نام في المكان الذي وصل إليه، لم ينشخل بالعودة إلى وطنه؛ فهو لا يحب مكانه القديم و لا يكر هه. ويبدو أن ما وصل إلبه كان رمالاً متحركة، وربما فخًا لكهف عميق مدفون تحت الأرض، المهم أنه من يومها..

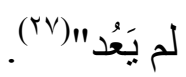
تلك الملامح الوصفية التي رسمت أبعاد الثخصية وأكدت لامبالاتها بأي شيء، جعلت من الحدث الختامي في المسار السردي نهاية حتمية نتيجة اللامبالاة بالعالم وعدم التبصُّر بالو اقع المحيطو غياب الانتماء لوطن يكون مركزًا للوجود في العالم.

يُعد العنف ضد الأبرياء الذين لم يرتكبوا ما يستوجب العقاب من أخطر الآفات التي

تهدد أمن مجتمعاتتا وتعوق تقدمها نحو المستقبل، وتتعدد مظاهر العنف وأنواعه، ومن أخطر ها استخدام الدين ذريعة لتبرير العنف ضد الآخر، و إدانة نللك الظواهر واجب ثقافي ووطني و إنساني على كل صاحب رأي، أولاً لأنه يتنافي مع الإنسانية، وثانيًا لأنه من أكثر العراقيل التي تحول دون بلوغ المستقبل الآمن، وذلك النمط من العنف سلوك همجي مرفوض ولو كان ضد حيوان أعجم.

تعرض قصة "هذا ما حدث" لظاهرة تبرير الاعتداء على الآخر باسم الدين، من خلال ما حدث للثخصية الساردة/ الكلب محروس الذي يعيش وسط أسرة قروية طيبة حياة آمنة، يساعد السيدة زوجة صاحبه في مسئولية "حراسة الخبز وتخويف القطط و الماعز، وحتى العصافير من الاقتراب منه"(^^r)، ويساعد الابنَ ناصر "في رعي الماعز

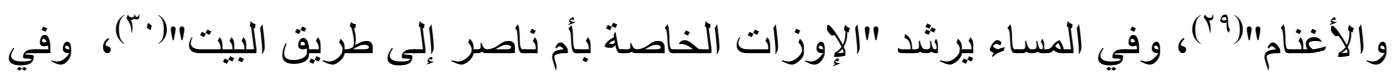
الليل يسهر لحماية البيت. 


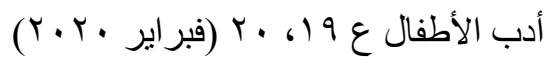

التشكيل السردي في أدب الأطفال

و الملامح التي تسند إلى الثخصية الرئيسة تتجاوز الدور الموضوعي على المستوى

السطحي للبنية السردية، ونؤسس في البنية العميقة لذات مسالمة عاملة تفيد مجتمعها/ الأسرة الطيبة وتستفيد بالمأوى و الأمان في العيش بينها، ومن هنا تتخذ شخصية الكلب محروس بُعدًا إنسانيَّا يعمق مأساته ويدين العنف إدانة دامغة.

بعتمد البناء السردي على تقنية السارد الثخصي المتكلم بضمير الأنا، ويتم تقديم الحدث من خلال التبؤر الداخلي من وجهة نظر الثخصية الرئيسة/ الكلب محروس الذي يصور تغير الأوضاع مع مجيء الجيران الجدد: "كانت أسرة سعيد ـ الجار الجديد- أسرة قاسية، أو لادهم أثقياء يتصرفون بغر ابة وعنف"("آ).

تتوالى وقائع الاعتداء عليه تباعًا، فابن الجار الجديد يضربه بقدمه في بطنه ذات مرة، وفي مرة أخرى: "اقترب جارنا مني بهدوء، تخيلتُ أنه يحاول التودد لي، أو حتى الاعتذار، لكن بعد لحظة اكتشفت حقيقة الأمر، كان الولا يمرر الحبل الليفي حول رقبتي، وراح يضيق الحبل ويسحبني، أنا أقاوم الحركة ولا أريد أن أهجم عليه"(rr). كما يتعرض لمحاولةٍ للقتل بالسُّم، وفي اليوم الأخير : "مع ظهور الفجر أخذتني غفوة قصيرة، استيقطت بعدها على رداء يلفّ جسمي، بدا الأمر لي كأنه كابوس، لم أستطع أن أنبح، كنت مخنوقًا من الظلمة وقلة الهو اء، بعد قليل انفتح الجو لأجد نفسي وسط مجموعة من الأولاد أصدقاء ابن جارنا سعيد. كان في يد كل منهم عصا غليظة، كلما ضربني أحد نبحتُ وجريتُ نحوه هرب وضربني الآخر من الخلف، أستدير فيهرب ويضربني غيره، ظلَّ الأمر هكذا، أنا أتألم و أصر خ، و هم يضربون ويضحكون" (r"). وتُعد وقائع العنف تلك تمثيلاً سرديَّا لنسق فكري مغلوط كامن خلفها تصدر عنه، هو ليس عنفًا عبثيَّا صبيانيَّا بدافع اللهو، و إنما عنفُ يستند في تبريره إلى فهٍٍُ مغلوط للدين، ويسند في حماية أفعاله وشر عنتها إلى سلطة الأب/ سعيد الذي يرى أن ما يقوم به أو لاده من عنفٍ وإيذاء واجب شرعي، ويكثف المقطع التالي عن ذللك النسق الفكري المغلوط الذي يبرر استخدام العنف باسم الدين: "في الصباح وقف صاحبي يكلم السبد سعيد بهدوء، قال له: لو سمحت، امنع أولادك من إهانة كلبنا، هذا لا يصح ولا يجوز، وهو حر ام. ضحك سعيد، وقال: حر ام؟! ليس حر امًا، إن الكلب نجس، ويستحق كل أذى"(؟广). 


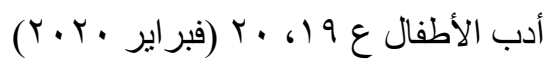

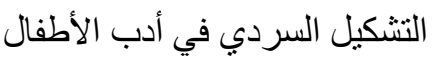

و إذا كان المجتمع يطمح إلى مستقبلٍ أفضل، فعليه أن يذلل ما يعترض طريقه من

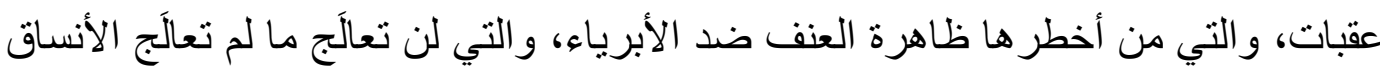
الفكرية المغلوطة الكامنة ور اءها التي يجب أن تصحح أو لاً حتى يستقيم طريق الستقبل. ثانيًا - الزمكانية:

تعبر مقولة الزمكانية عن الزمان في ارتباطه بالمكان، وهي تُعد من المقولات

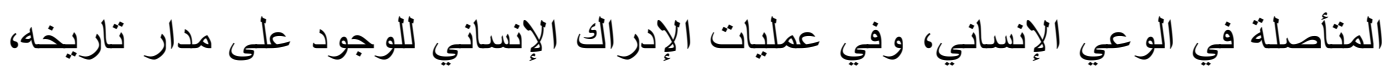

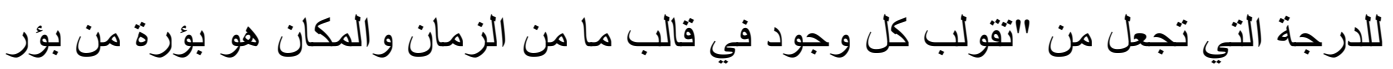
الوعي الإنساني في كل مستو ياته: من الحس المشترك إلى التفكير العلمي إلى الفكر الفلسفي.

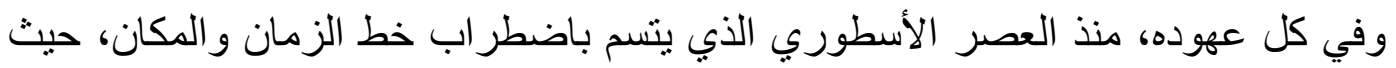
تقع حوادث الأسطورة في إطار زماني غير منطقي، وتنتقل عبر أمكنة لا يمكن تصور

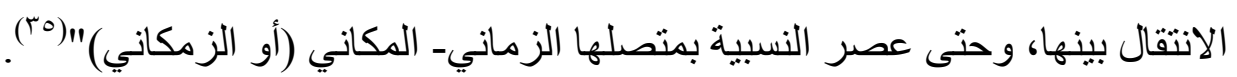

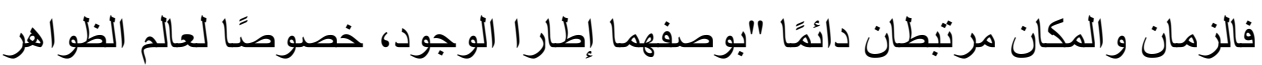

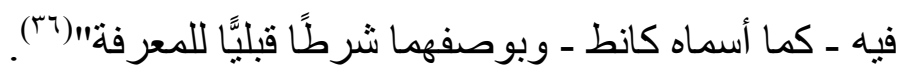
عرضنا في مبحث الثخصية والحدث للأنساق المضمرة الفاعلة التي تكثف عن طبيعة ودوافع الثخصية فيما تقوم به من ممارساتٍ سردية على مستوى الحدث، وتلك ماتك الأنساق الكامنة وتمثيلاتها السردية لا تنفصل عن إطار ها الزمكاني الزمان/المكان، وتنعكس آثارها الجلية على ملامح التشكيل السردي، وسوف نعرض في مبحث الزمكان لنسقين

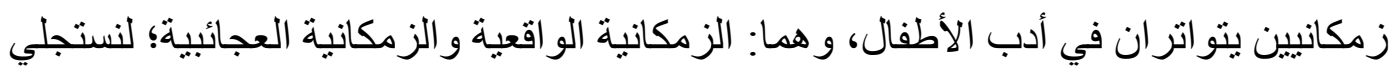

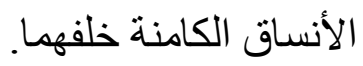

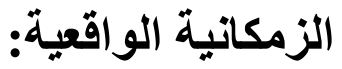

تستمد الزمكانية الو اقعية مقوماتها في صورتها الأولى النقية من المكونات الزمانية

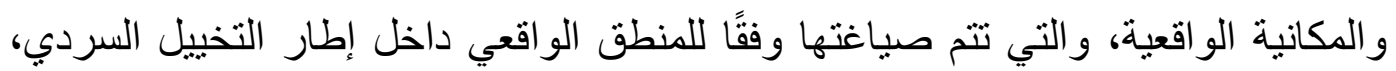

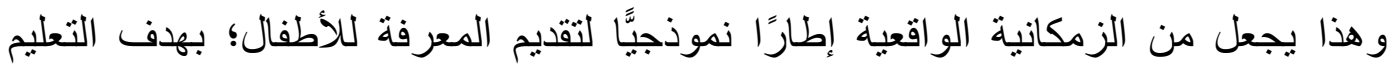

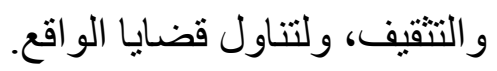

انطلقت سلسلة "فرقة الناشط علي" من مسعى تثقيفي يهدف إلى تعريف الأطفال

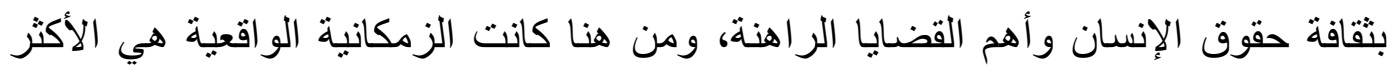

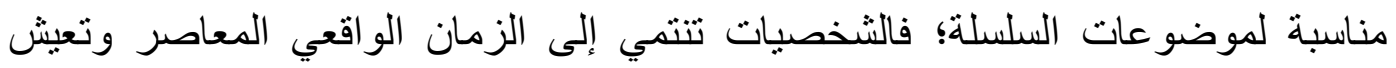




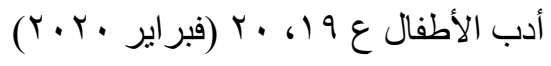

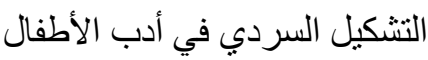

وتنتقل بين أماكن واقعية، في صياغة منطقية تسعى إلى توصيل الرسالة التثقيفية بأهم

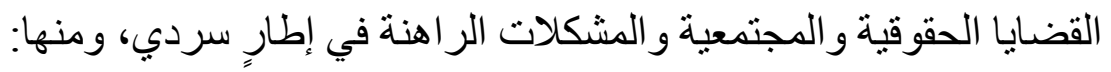

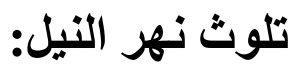

تُعد الأنهار في إفريقيا من أهم شرايين الحياة وسبل التنمية، واتخذت قصة "أحزان مر اكبي" من نهر النيل موضوعًا لبنائها السردي، وموضوعًا للمادة التثقيفية وعرض مشكلة التينة تلوثه.

ويبدأ الإطار السردي عندما تقرر "فرقة الناشط علي" القيام برحلة نبلية إلى القناطر

الخيرية، ويكون الذهاب بالمركب الثر اعي للعم إبراهيم، وفي الطريق ينم توظيف الحوار في تقديم المحتوى التثقيفي، فتسأل "مس منى" التي صاحبت الأطفال في رحلتهم: "مين الثشاطر اللي هيكلمنا عن نهر النيل!! فرفع الجميع أيديهم؛ وكأنهم في الفصل، فأنشارت إلى لى لفي علي فقال: نهر النيل هو أطول أنهار الكرة الأرضية، وطوله .077 كيلومترًا، ويقع في

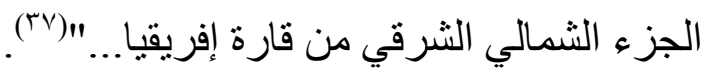
بعد تقديم المحتوى الثقافي ينتقل السرد لمشكلة تلوث ماء النيل، ويبدو الحزن و التأثر

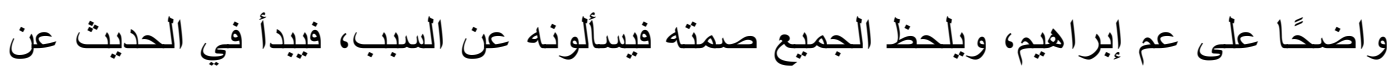

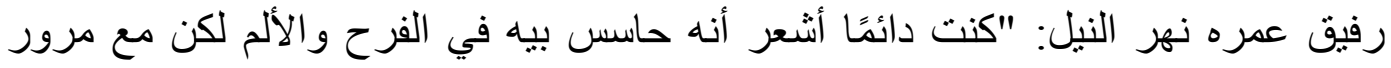

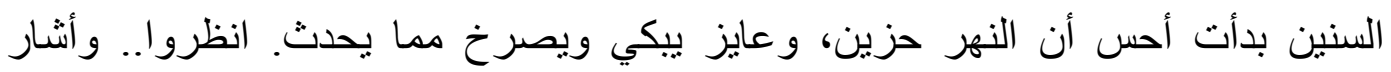
المر اكبي إلى الثاطئ: هذه المواسير الضخمة تلقي بفضلات المصانع كل يو وفي كل مكان في النيل.. انظروا، وأنشار إلى الكثير من علب العصائر الفارغة، وغيرهاتها من المهملات

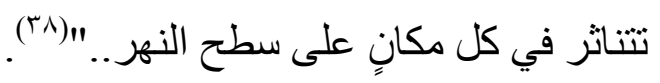
مشكلة تلوث البيئة:

في "مذكرات خضرة" ينم أنسنة الأشياء فيصير الاخان وحشًا عملاقًا، وتمتلك الثجرة ذاكرة ولسانًا ناطقًا، وذللك من خلال تقنية الحلم التي تسمح بتلك الأنسنة بدون الخروج عن المنطق الو اقعي داخل الزمكانية الو اقعية، فعندما ينام علي يرى دخانًا من عو ادم

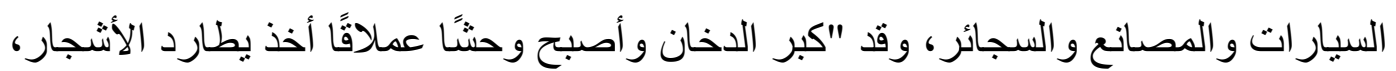

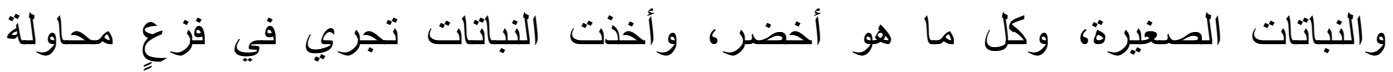

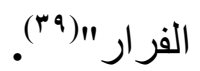




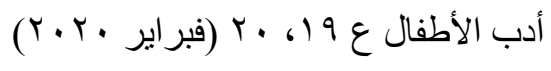
النشكيل السردي في أدب الأطفال

أنسنة الثجرة يجعل منها ساردًا يتم تبئير السرد داخل الحلم من وجهة نظرها، فيتم

عرض مشكلة التلوث البيئي من وجهة نظر الذات المتضررة من التلوث، فيكون الوقع أكثر تأثثرًا، ويأتي العرض في تتابعٍ زمني خطي، يبدأ من الماضي إلى الحاضر مصورًا كيف انقلبت الحياة من السعادة والجمال إلى الوحدة و البؤس، بسبب اعتداء الإنسان على المساحات الخضر اء و إطلاقة عو ادم الدخان بدون قيود.

تتهار الشجرة باكية: "أشعر يا علي أنني سأموت دون أن يبكيني أحد؛ لأن أهلي كلهم قد سبقوني، و أنا سألحق بهم قريبًا. ثم مدت خضرة أحد فروعها إلى علي، و أمسكت بيديه

$$
\text { وهي تقول: أرجوك ساعدني يا علي"(•؛) }
$$

بعقب الحلم الانتقال إلى المستوى الواقعي للتخييل، فيلتقي أعضاء فرقة الناشط علي ويقررون مناقتة قضية التلوث البيئي، ويلتقون الأستاذ طاهر مدرس الزر اعة؛ ليتم الحديث

عن قو انين حماية البيئة وسبل تلك الحماية.

\section{الزمكاتية العجائبية:}

تتشكل الزمكانية العجائبية في صورتها النقية النمطية من زمانٍ مطلق ومكانٍ عجائبي وصياغة لتشكيلات السرد وفق منطق يخرق قانون الواقع بصورةٍ أو أخرى، وينتمي العمل السردي إلى الزمكانية العجائبية عندما تكون هي الإطار الرئيس لمسار الخط السردي الرئيس؛ إذ قد تحضر الزمكانية العجائية بصيغٍ متعددة جزئيًا داخل الزمكانية الواقعية كما في توظيف تقنية الحلم، ولكن ذلك لا يُخرِج العمل عن واقعيته، وللزمكانية العجائبية أنماطُ عدة مشتقة من نمطها الرئيس، سوف نعرض لنمطين منها، و هما: زمكانية

$$
\text { الو اقع الافنر اضي، وزمكانية الحكي الثعبي. }
$$

\section{زمكاتية الواقع الافتر اضي:}

أخذت صورة العالم كما يتم تقديمها للأطفال حيزًا من اهتمام ومناقثات الباحثين و المهتمين بأدب الأطفال، فالعالم به الخير كما يوجد به الثر، محبو السلام ومحركو الفتن و الحروب، والقطبان متلازمان في الحياة قد ينتصر أحدهما ردحًا من الزمن لكنه لا يقضي على الآخر، وتلك طبيعة الحياة الإنسانية منذ وجدت، وكان السؤال الأدبي هو: هل نقدِّم الشر في أعمال أدب الأطفال أم أن ذلك يُتقِل كاهل الطفل بما فوق و عيه؟ ويمكننا صياغة الإجابة في صورة سؤال أيضًا: هل نقدِّم للطفل صورة عرجاء عن العالم تقف على قدٍ و احدة، أو صورة ملائكية لا يلبث أن يكتشف زيفها عندما ينضج و عيه وتتفتح مداركه؟ ومن هنا سعى 


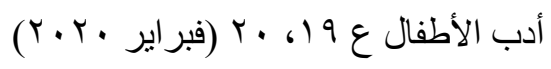

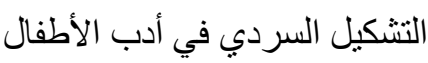

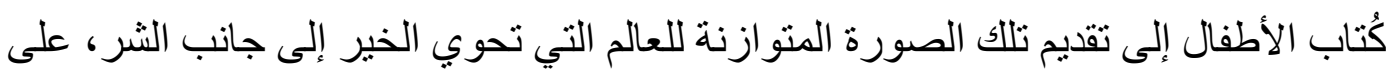

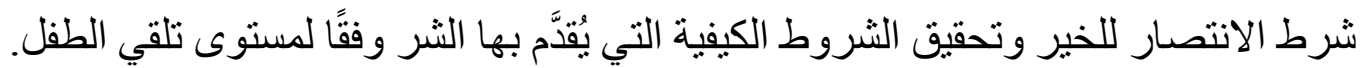
وسعى كُتّاب الأطفال إلى البحث عن صيغ مناسبة لتقديم الثر في أعمالهم، كان منها

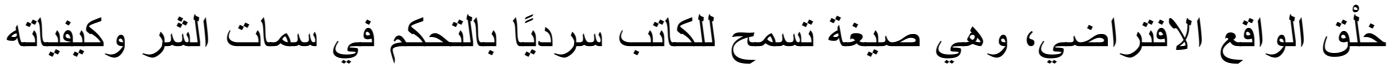
بما يناسب مستوى التلقي لاى الطفل.

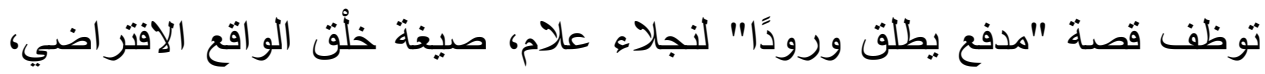

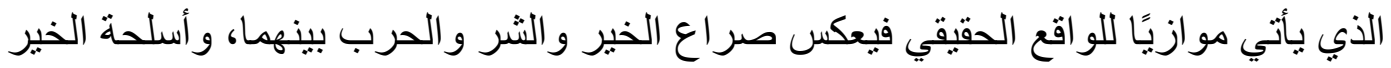

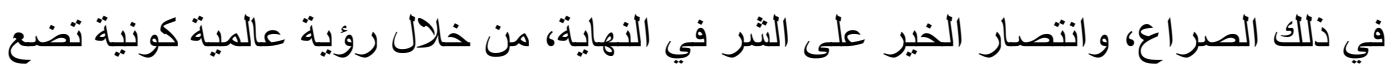
الأطفال في بؤرة الفعل و العمل وتجعل الانتصار مر هونًا بهر. تتخذ القصة زمكانيتها في المطلق، مطلق الزمان ومطلق المكان، مع إرهاصاتٍ تشير إلى الزمن و المكان المعاصرين، ويشمل الفضاء المكاني أطفال العالم، حيث تجمعهم مدينة الأحلام، ويتوحد داخلها حُلم جميع الأطفال. الليلة يقرر "حلوم" حارس مدينة الأحلام أن يرى الأطفال جميعهم نفس الحُلم في

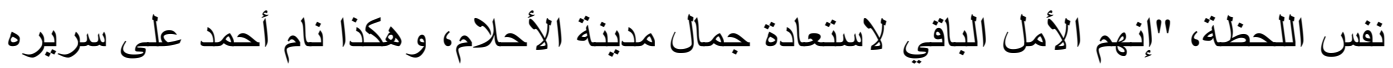

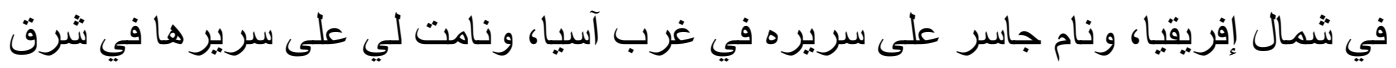
آسيا، ونام صموئيل على سريره في جنوب إفريقيا، ونامت كارولين على سرير ها في وسط إنى

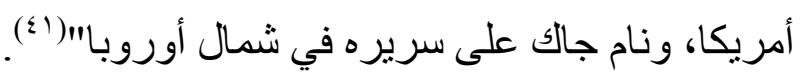
وكان هذا القرار لمحاربة أرض الثر، فقد كان لهان "هناك منطقة في نهاية مدينة

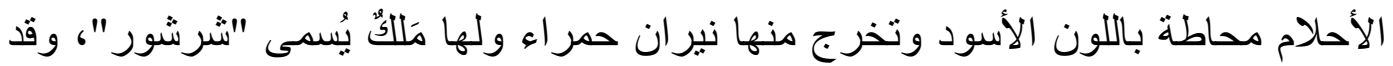
حاول شرشور كثيرًا أن يحول مدينة الأحلام كلها إلى منطقة شريرة تجعل كل من يدخلها لا

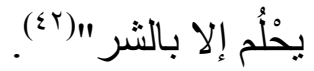

ويستطيع شرشور بمساعدة أعوانه أن يزينوا الأحلام الثريرة لكل من يدخل مدينة الأحلام "فانتشرت أحلام بها دماء وقتل ونيران وقنابل وعنف، ولم يَعُد الإنسان يفرق بين

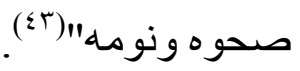
وأدرك الأطفال في كل العالم رسالة حلوم، وقرروا أن يحاربوا الأحلام الشريرة بالأحلام الجميلة الخيرة، "حلم أحمد بالعدل والمساو اة، وحلمت لي بالخضرة في كل وله مكان،

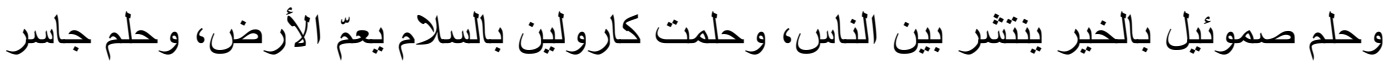




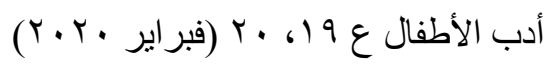

التشكيل السردي في أدب الأطفال

بالجمال يكسو كل شيء، وحلم جاك بالحب يجمع الناس، وصعدث الأحلام.. صعدت إلى

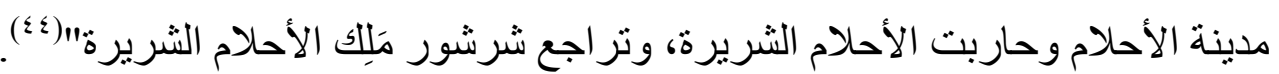
تختتم القصة بانتصار قيم الخير والجمال على الشر والقبح؛ فالأطفال جميعهم قد حلموا "بمدفع كبير.. كبير جدًا يطلق ورودًا حمر اء وبيضاء وصفر اء وبنفسجية، وظل الحُلم يتكرر داخل رأس كل طفلٍ، حتى غطيت أرض مدينة الأحلام بالورود، ودُفِن فيها شرشور و أعو انهه و انتهى الخراب، و عاد لمدينة الأحلام زهو هاو جمالها"(ه؛.).

\section{زمكانية الحكي الثعبي:}

تُعد الشعوب الإفريقية من أغنى الشعوب بالحكايات الشعبية، والتي كانت مصدرًا للأدب العالمي للأطفال، كما تعرضت للسطو من قِبل الاستعمار ، ويذكر أحد المستشرقين "أن الاستعمار الأوروبي سرق من القارة الإفريقية ما يزيد على ربع مليون حكاية شعبية"("َ)، هذا وما زالت الشعوب الإفريقية لم تتعرف على أدبها الشعبي فيما بينها، ولعل تللك تكون توصية للبحث بدعوة المؤسسات المعنية بأدب وثقافة الطفل أن تتخذ من التدابير ما يكثف عن تلك الكنوز التقافية التي هي محصلة إنتاج قريحة وفطرة الثعوب على مدار الأجيال، وتوصيلها للأجيال الناشئة.

في الحكاية الثعبية يتم تنميط الثخصيات، وتقديمها وفقًا لبعدين ثنائين، فالخير المطلق مقابل الثر المطلق، و الجمال الفائق مقابل القبح الثديد، و الثجاعة و الوفاء في مقابل الخبث و الخسة والتوحش، ويتم الانتصار للخير عن طريق البطل الذي يثبت استحقاقه للنهاية السعيدة وحصوله على المكافئة، كالزواج من الأميرة أو الفتاة فائقة الجمال، أو الوصول إلى الكنز... إلخ. وفي هذا الإطار يتم توظيف المكان توظيفًا سرديَّا يؤكد استحقاق البطل وشجاعتة وإصر اره في التغلب على العقبات و الصعاب. في حكاية "لونجا" الحكاية الشعبية الجزائرية الشهيرة، يتم توظيف المكان عدة توظيفات مركزية ترتبط بالأحداث النوى في المسار السردي، في إطار الزمكانية العجائبية، فالزمان مطلق و المكان عامل حاسم في الأحداث وفي بناء الثخصيات، تبدأ الحكاية في قلعة عظيمة تضاهي السماء، حيث "يعيش الملك وزوجته وابنهما الأمير زهَّار الذي عرفته البلدة بمرو وته وشهامته وطيبة قلبه وشجاعته الفائقة، وبجوار القصر يسكن شقيق الملك شقران"('汭) و الذي يطمع فيما عند أخيه؛ فيدبر مكيدة للخلاص من الأمير زهار ابن أخيه الملك. 


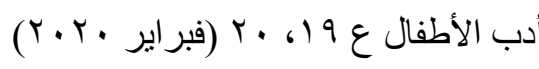

التشكيل السردي في أدب الأطفال

يستعين بالعجوز الداهية التي توقع في قلب الأمير حب لونجا الفتاة الأسطورية فائقة

الجمال "ابنة العملاق المتوحش التي تعيش في غياهب الدنيا بأقصى المعمورة، حيث لا أحد يمكنه أن يصل إليها كي يرى سحرها وروعتها؛ لأنها تقيم وسط متاهات الموت و الهالك"(^^)، فيمتطي الأمير عربته التي يجرها حصانان قاصدًا ذلك المكان الموحِّ، وبذلك فإن جر أة الأمير وقبوله الذهاب إلى ذلك المكان وتحدي المخاطر دلائل سردية على شجاعته وبر هان على صدق حبه لفتاته.

يمتلى الطريق بالمخاطر، ويقابل الثيخ الحكيم الذي يحذره من "الصخرة العجيبة التي تفتح وتغلق بسر عة غريبة، وفي الفضاء ترقص الوطاويط رقصة الموت"(9؛)، ويكون نجاح الأمير في اجتياز تلك العقبات و المخاطر المكانية دليلاً على مهارته وذكائه، حتى يصل إلى حيث تعيش لونجا في "قلعة ذات شكلٍ عجيبٍ مريب، كأنها رؤوس أسود و أنياب وحوش من العهد القديم، تقشعر لها الأبدان وتفزع لمنظر ها النفوس.. وجد أمامه كلبة ضخمة هجمت عليه فرمى لها قطعة لحمٍ كان قد استلمها من بد الثيخ المدبر، ثم داعبها بمرونة وليونة حتى هدأ روعها فسكنت حركاتها، ثم بدأ الأمير يصيح مناديًا: لونجا، أيتها الحسناء هيا اخرجي..."(·)، فيؤكد بذلك حكمته ووضع اللين في موضعه كما أن للقوة موضعها. وتز اه لونجا فتقع في حبه وتقرر العودة معه إلى مملكته، وفي طريقهما يختطف نسر ضخم الأمير ويُحلِّق به إلى مكانٍ مجهول، فتنعكس الأدوار السردية ويأتي الدور على لونجا لتبرهن على حبها للأمير، كما برهن على حبه لها، ويكون نجاحها في الوصول إلى مكان اختطافه.

ويكون الطريق الثاق والطويل الذي قطعته لونجا دليلاً على حبها و إخلاصها للأمير، فقطعت في طريقها إليه "البساتين والحقول والجبال والوديان والسهوب وبلاد القفار "(10)، حتى وصلت إلى مخبأ النسر ، و "(قتربت من الثجرة الكبيرة، فسمعت أنبنًا خافتًا، خفق قلبها، إنه الأمير زهار، أسرعت نحو الثجرة لكن النسر العملاق كان أسرع منها، حيث حمل الأمير وحلَّق في السماء"(oror)، فيجيها الأمير زهار : "عليك بذبح خروفٍ سمين ونركه عند النهر"(م+or)، وقامت "لونجا بتنفيذ وصيته، "و عندما أكل النسر الخروف وقع طريحًا على الأرض حيث لا يقوى على الطيران من التخمة"(ه)، وبذلك أنقذت لونجا الأمير زهار من الطائر الجارح ثم عكفت على مداو اته حتى تم شفاؤه. 


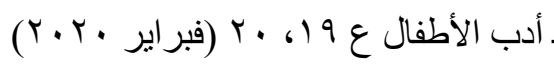
التشكيل السردي في أدب الأطفال وكما كان المكان هو البداية التي حفزت وانطلق منها الحدث السردي، فقد كان المصب الذي انتهى عنده مسار الحدث، حيث ينتصر الخير وتعمّ السعادة، ويعود الأمير زهار ولونجا إلى المملكة، "وباءت الخطة الجهمية للعجوز الماكرة المدبرة للمكيدة مع شقيق الملك شقران بالفشل، وكان جزاؤهما خيبة الأمل التي قتلتهما حسرةً وندمًا على ما فعلا، وعاش القصر الأفراح و الليالي المِلاح محتضنًا الأمبر ولونجا في سعادة وهناء"(00). ويعد ذللك الارتباط السردي بين المكان والثخصية والحدث تمثيلاً لنسق الارتباط الوثيق بين الإفريقي بأرضه ووطنه والذي يشعر بأنه امتداد مكاني لذاته، وتمثُّل الخاتمة السعيدة في نهاية الحكاية الثعبية نسق محبة الخير والطيبة المتأصلة في الإنسان الإفريقي المسالم، و الذي يرى المكافأة تنتظر القلوب الخيرة في نهاية المطاف، كما أن العقاب هو النهاية المُنتظرَة لكل من سعى بالثر و العدوان. 


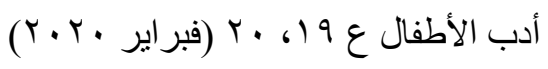

التشكيل السردي في أدب الأطفال

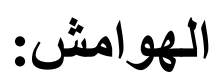

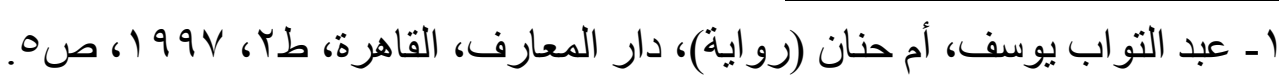

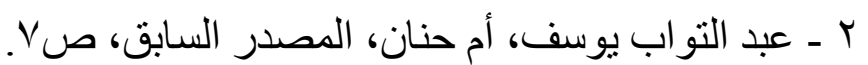

r - عبد التواب يوسف، أم حنان، المصدر السابق، صو،

ـ ـ عبد التواب يوسف، أم حنان، المصدر السابق، صلو ل .

ـ ـ عبد التواب يوسف، أم حنان، المصدر السابق، صلو.

7 - يعقوب الشاروني، قصة "إر ادة الله" من مجمو عة أبطال أرض الفيروز، رسوم:

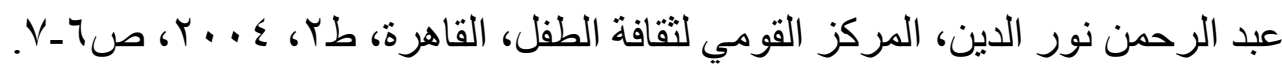

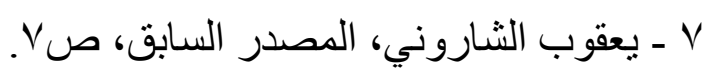

1 - يعقوب الثاروني، قصة "بطولة شهيد" من مجمو عة أبطال أرض الفيروز، ص • 1. 9 - عبد التواب يوسف، عميل في المصيدة (رواية)، رسوم: أشرف عيد، دار المعارف،

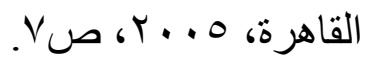

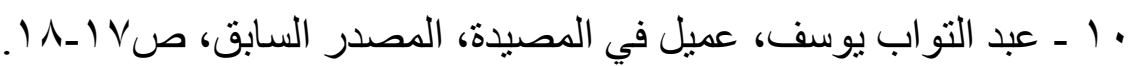

1 ـ ـ عبد التواب يوسف، عميل في المصيدة، المصدر السابق، صه|

r ا ـ محمد سعيد العريان، سلسلة مغامر ات أرنباد، ج) ، دار المعارف، القاهرة، ص 1. ب ا ـ أحمد طوسون، أحلام السيد كتاب "قصة"، الهيئة المصرية العامة للكتاب، القاهرة،

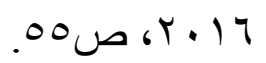

ع ا ـ أحمد طوسون، أحلام السيد كتاب، المصدر السابق، ص • ع.

10 ـ أحمد طوسون، أحلام السيد كتاب، المصدر السابق، ص. • 7.

ا 1 - فاطمة المعدول، زينة تصعد القمر (قصة)، رسوم: مجدي نجيب، المركز القومي

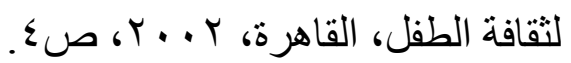
V ـ فاطمة المعدول، زينة تصعد القمر، المصدر السابق، صلو ل ^1 ـ فاطمة المعدول، زينة تصعد القمر، المصدر السابق، صی^. 9 ـ ـ فاطمة المعدول، زينة تصعد القمر، المصدر السابق، ص^ي. • . ـ فاطمة المعدول، زينة تصعد القمر، المصدر السابق، ص9. ا Y ـ فاطمة المعدول، زينة تصعد القمر، المصدر السابق، ص • 1. 
Y Y ـ فاطمة المعدول، زينة تصعد القمر، المصدر السابق، صY I . r ـ فاطمة المعدول، زينة تصعد القمر، المصدر السابق، صب ا.

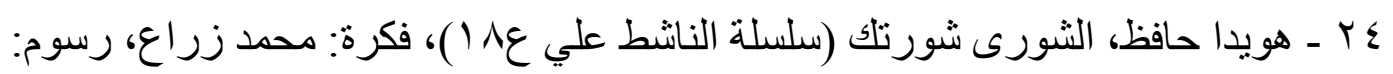

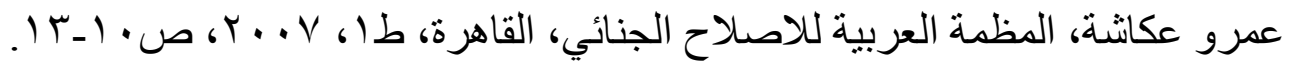
ه ـ أمل فرح، أين اختفي آخر الديناصور ات (قصة)، رسوم: إيهاب شاكر، الهيئة المصرية

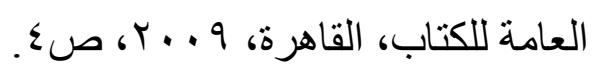

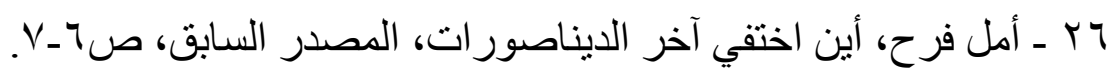

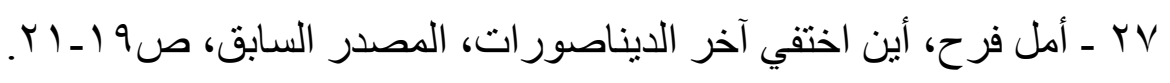
^ץ ـ أمل فرح، هذا ما حدث (قصة)، رسوم: نجيب فرح، الهيئة المصرية العامة للكتاب،

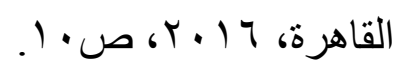

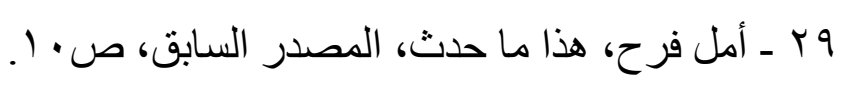
• " ـ أمل فرح، هذا ما حدث، المصدر السابق، صب أ. וr ـ أمل فرح، هذا ما حدث، المصدر السابق، صلو أ.

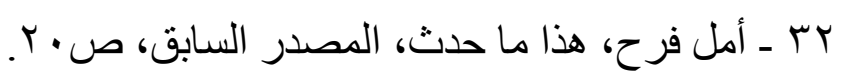
rr ـ أمل فرح، هذا ما حدث، المصدر السابق، صبr. צr ـ أمل فرح، هذا ما حدث، المصدر السابق، صهم ا. هب - يمنى طريف الخولي (دكتور)، الزمان في الفلسفة والعلم، الهيئة المصرية العامة

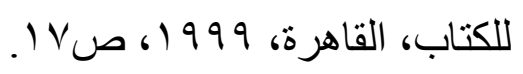

דr - بمنى طريف الخولي (دكتور)، المرجع السابق، صو 1 ا. V - محمد زراع، أحزان مراكبي (سلسلة الناشط علي عاب)، رسوم: عمرو عكاثة،

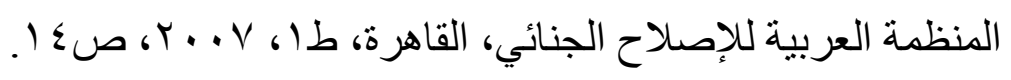

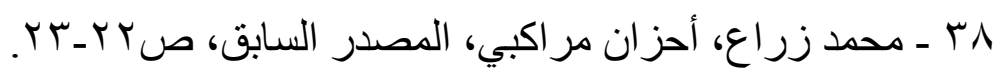
q ـ - هويدا حافظ، مذكرات خضرة (سلسلة الناشط علي ع^)، (فكرة) محمد زراع، رسوم:

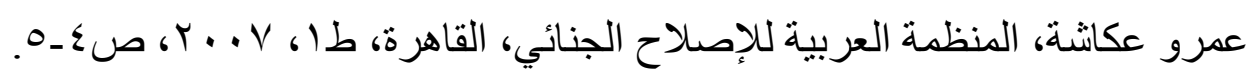
• ـ ـ هو يدا حافظ، مذكر ات خضرة، المصدر السابق، صس ا. اء ـ نجلاء علام، قصة "مدفع يطلق ورودًا" من مجموعة الأمنيات المضيئة، الهيئة العامة لقصور التقافة، القاهرة، سلسلة قطر الندي، ع • ب ، صع ا . 


$$
\begin{aligned}
& \text { r ـ ـ نجلاء علام، المصدر السابق، صr ا . } \\
& \text { rـ ـ نجلاء علام، المصدر السابق، صس ا. }
\end{aligned}
$$

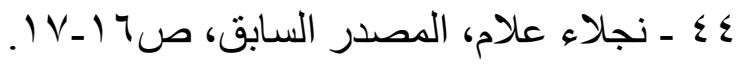

$$
\begin{aligned}
& \text { 0ـ ـ نجلاء علام، المصدر السابق، صى1 . }
\end{aligned}
$$

7؛ - عبد التواب يوسف، الحكايات الثعبية الإفريقية مصدر لقصص الأطفال العالمي،

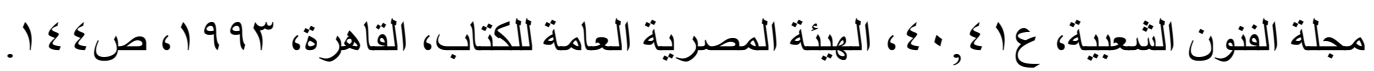
SV مبرك دراجي، وكمال بتوي، تقديم: عبد التواب يوسف، دار الحضارة، الجزائر، ب ...r،

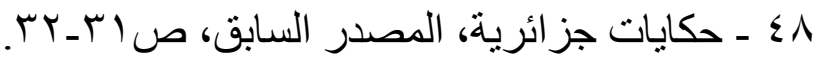
؟ ـ حكايات جزائرية، المصدر السابق، صسب. •0 ـ حكايات جز ائرية، المصدر السابق، صسب. 10 ـ حكايات جزائرية، المصدر السابق، ص^؟

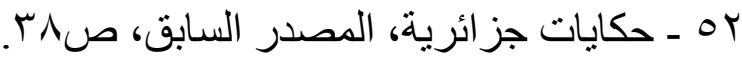

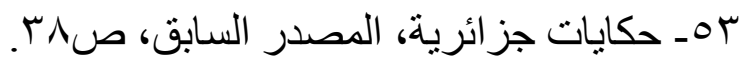
؟ه ـ حكايات جزائرية، المصدر السابق، صیمس. 00 ـ حكايات جزائرية، المصدر السابق، ص أـ. 